\title{
SEDIMENTATION STATUS OF LAKE VICTORIA: LOADING FROM RIVER MOUTH AND IN-LAKE SEDIMENTATION
}

\author{
${ }^{*}$ F. Mwanuzi ${ }^{1}$, D.K., Rutagemwa ${ }^{2}$, and A. Mathayo ${ }^{2}$ \\ ${ }^{I}$ Department of Water and Environmental Engineering, Box 35131 Dar Es Salaam, Tanzania \\ ${ }^{2}$ Water Quality Management Component, P.O. Box 211 Mwanza, Tanzania. \\ *Corresponding authorfmwanuzi@yahoo.com
}

\begin{abstract}
Lake sediments consist of the input of suspended solids by river discharges, the autochthonous produced particulate matter in the water column and the settled material on the lake bottom. The loading, transport, formation and decay of the sediments entering the Lake Victoria from Tanzanian side was monitored for the period 2000 to 2005 . The sedimentation study focused on; quantification of settling fluxes of particulate nutrients and organic carbon at the offshore(Pelagic) and near-shore(Littoral) monitoring stations. Monitored data on sedimentation rate and settling velocities has been sampled and analysed in the period November 2000 to March 2005. The mean sedimentation rate at littoral stations for total particulate phosphorous (TPP) was about twice as compared to pelagic stations. The same situation was observed for total particulate carbon (TPC), however, total particulate silica did not show a clear pattern of variability between littoral and pelagic stations though there was a general tendency of decreasing towards the pelagic stations. Mean value for TPC /TPP sedimentation rate ratio was 117.61 for littoral and 90.74 for pelagic stations respectively compared to TBSi/TPP which was 3.15 for littoral and 2.10 for pelagic stations. The results show that sedimentation rates are highest at the littoral stations compared to pelagic stations. The differences in settling velocities indicate that the settling material consists dead and living material with a contribution of diatoms. The stoichiometric composition of the settling material indicates nitrogen limitation and a non-dominance of diatoms.
\end{abstract}

Key Words: Lake Sedimentation, Littoral, Pelagic, Algal bloom, Nutrients, Lake Victoria, Carbon

\section{INTRODUCTION}

Sedimentation refers to settling of suspended particles when turbulence from water motion is no longer strong enough to keep them in suspension. When suspended solids exceed natural levels, they can become part of pollution, hence detrimental effect on water quality. With nutrient enrichment the biological production of organic particles is accelerated and that can lead to increased sedimentation as shown in Figure 2.

Human activities are the major cause of lake sedimentation because of accelerating soil erosion (from agricultural area), urban run-off and failure of wastewater treatment systems discharging to the lake. Further more, depending on physical characteristics of the water body, erosion from catchments, airborne inputs and biological activity they contribute to sedimentation processes.

The Lake Victoria has a terrestrial catchment area of about $197,500 \mathrm{~km}^{2}$, out of which $69,500 \mathrm{~km}^{2}$ is the lake itself, fifty one percent $(51 \%)$ of the lake area $\left(35,720 \mathrm{~km}^{2}\right)$ is found in Tanzania side while Kenya and Uganda share the rest part (Fig.1). It is the second largest in the world, is serving about thirty million people of the three riparian countries namely Kenya, Tanzania and Uganda.



Fig. 1: Lake Victoria Tanzania side. 
However, because of urban areas population increase and rapid growth of industries on the shoreline, poor agricultural system, deforestations and bushfires, the lake is experiencing environmental stress which in turn threats the future beneficial uses of the lake.

\section{(i) Autochthonous (the produced particulate matter in water column)}

The production of macrophytes (aquatic plants) and phytoplankton (free-floating algae) leads to organic debris that eventually sinks to lake bottom

\section{Sources of sediments}

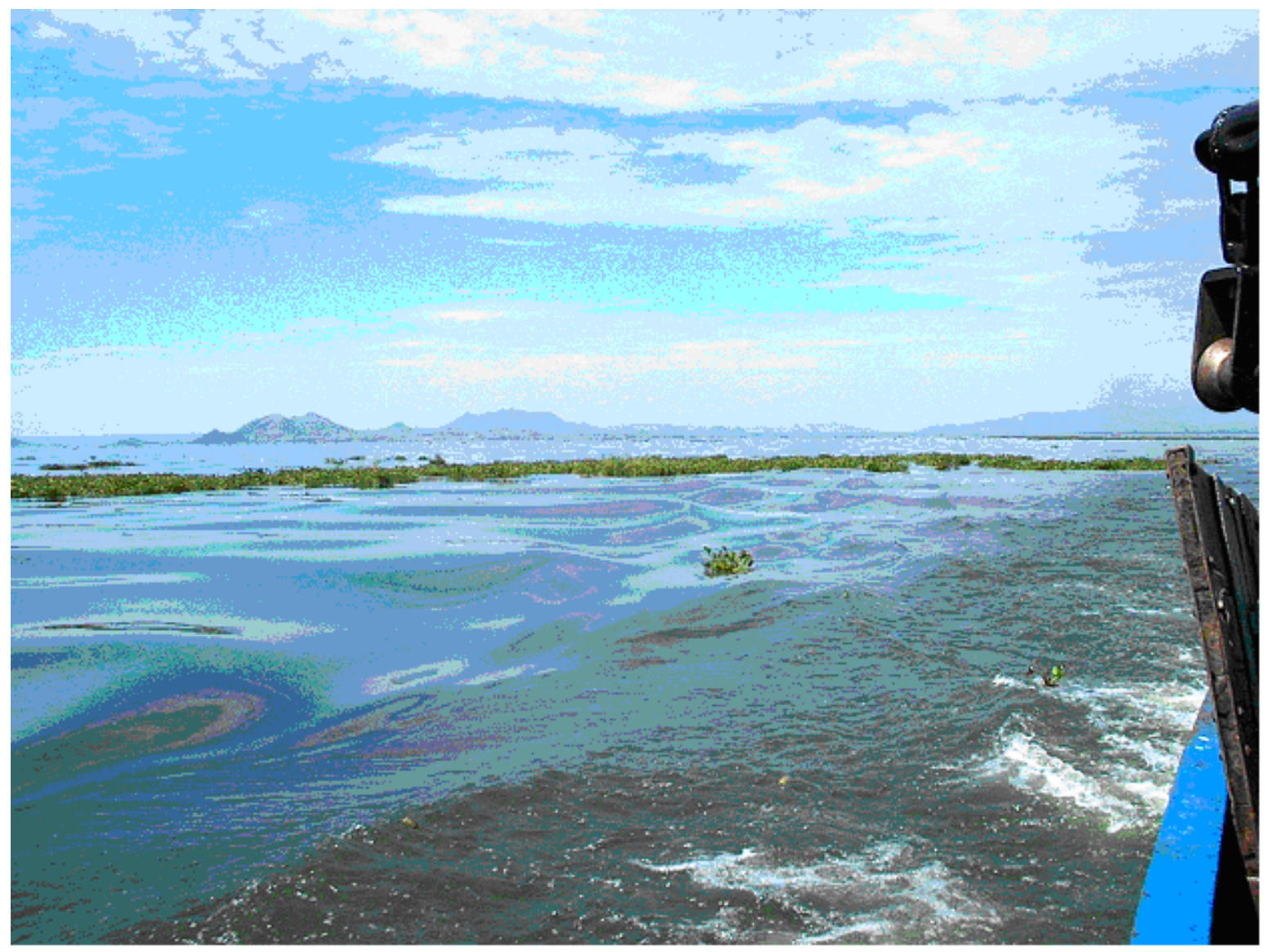

Fig. 2: A mat of algal bloom and water hyacinth.

\section{(ii) Allochthonous (Input of sediments through rivers and surface run off discharges)}

Soil erosion in Lake Victoria Catchment has been amplified by human activities including poor land use in agricultural areas, e.g overgrazing of large heard of domestic animals (particularly cattle, goats and sheep) and bush fires. Present agricultural practice accelerates soil erosion that adds to the sediment load into lake Victoria. Figure 3 and 4 shows land use changes after soil erosion (gullies) which might be the outcome of poor agricultural practices and other human activities including pastoral activities. 


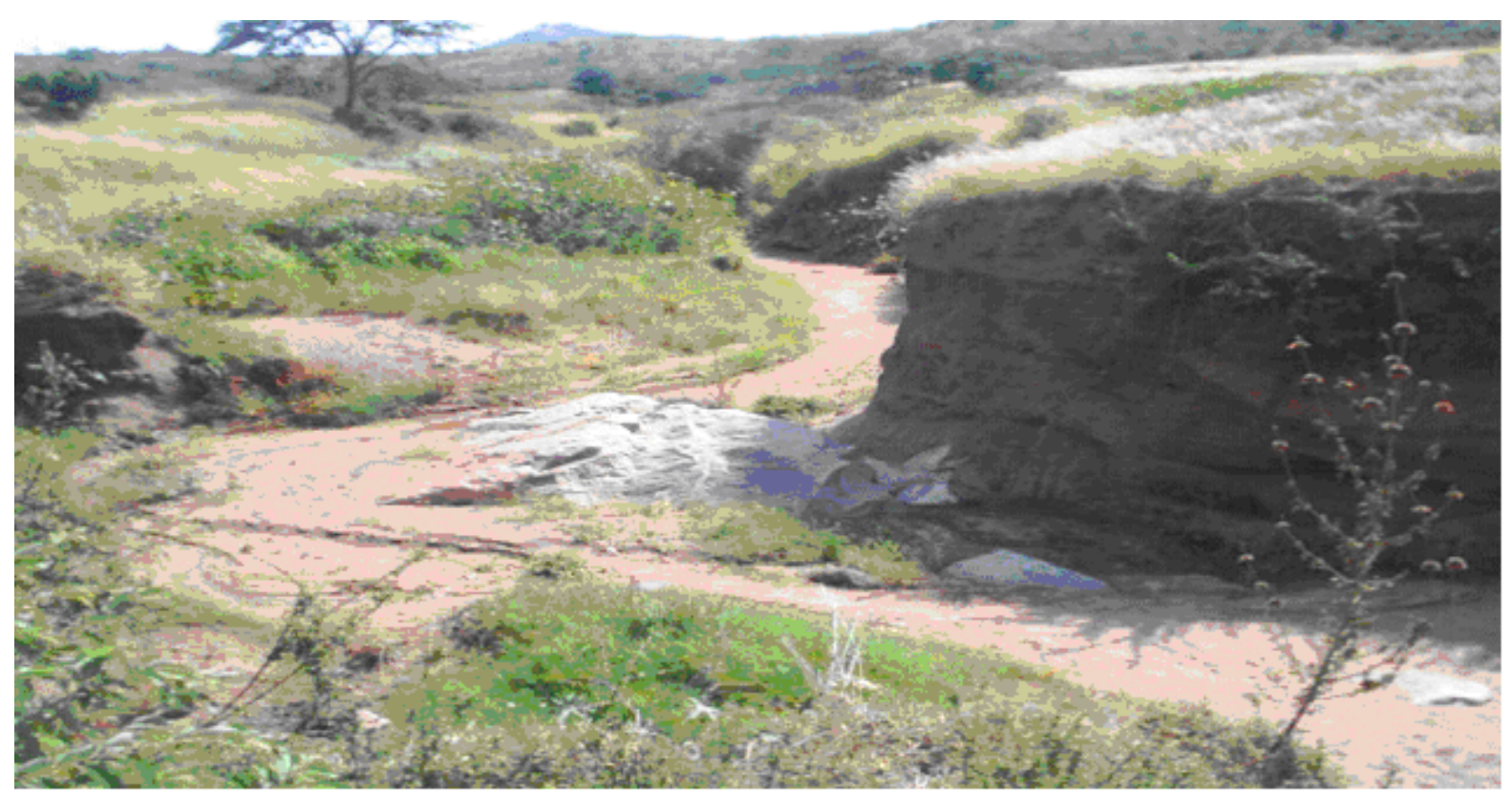

Fig. 3: Widened valley due to accelerated soil erosion that adds to the sediment load into lake Victoria (Nyamatoke Village - Bunda).

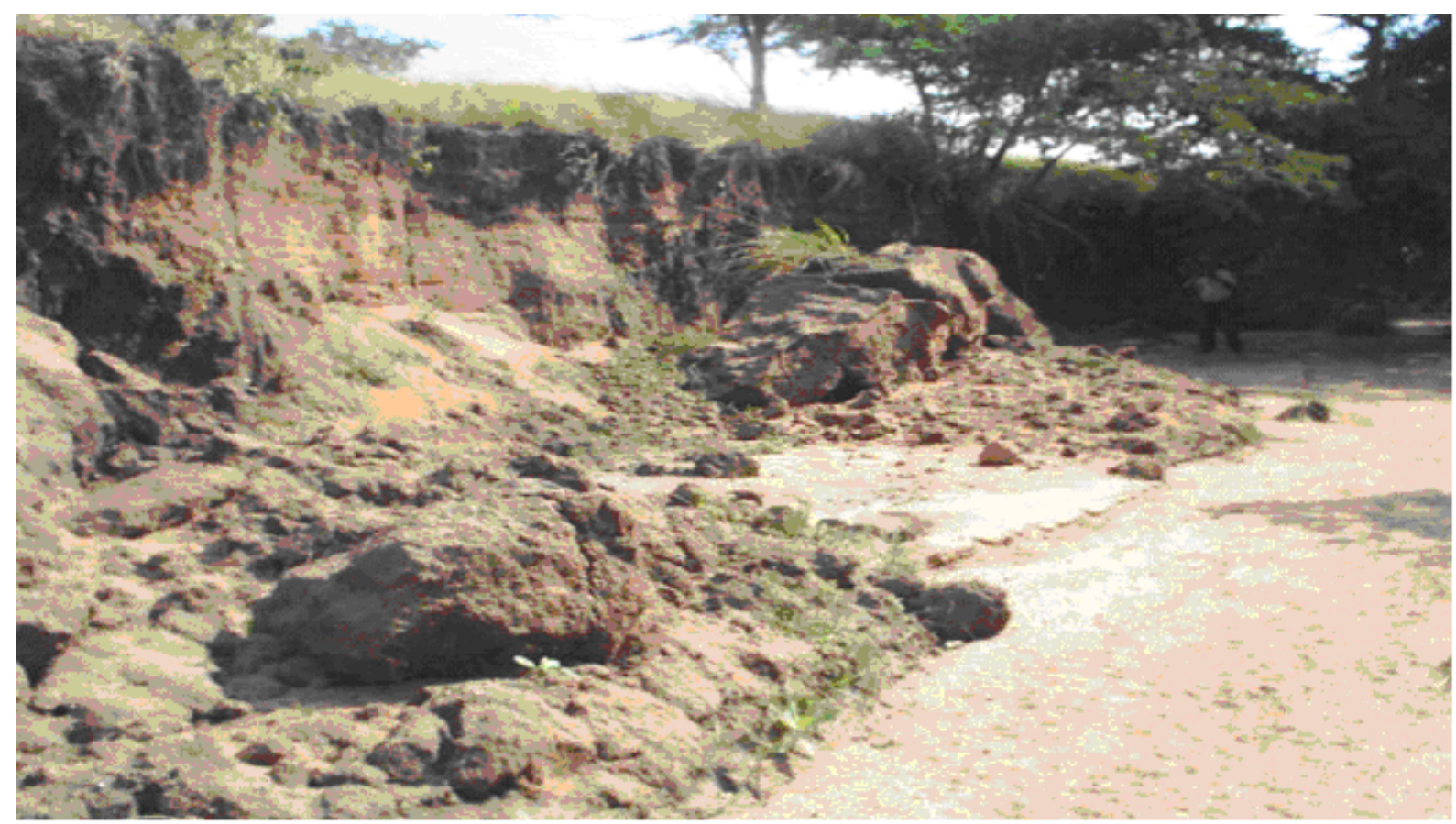

Fig. 4: Chipped soil due to erosion at valley mouth that adds to the sediment load into lake Victoria (Nyamatoke Village-Bunda).

\section{Sediments effects on Eutrophication}

When sediments are in suspension, they alter the native aquatic habitat by blocking light penetration, affecting water chemistry and changing the substrate where it is deposited. When plant material and other organic matter decompose, the process uses up dissolved oxygen required by native flora and fauna for their survivor. Decomposition of organic matter, which always accompanied by sedimentation, eventually goes to the bottom of the lake and causes the lake to undergo natural aging and in the long term fills in the lake basin. Lake Victoria, which is typically shallow and warm, is susceptible to sedimentation effects and aging because data collected so far with reference to human activities that take place around and within the lake favours the enrichment of nutrients hence high rate of sedimentation. Lake sedimentation study is important for the reason that it is an 
essential link in the chain of eutrophication processes and the nutrient mass balance.

In the sediment, mineralisation continues and dissolved nutrients are released to the pore water. Trough sorption equilibriums and molecular diffusion along concentration gradients the dissolved nutrients can move upwards or downwards participating in further microbial processes like bacterial uptake, remineralisation, nitrification and denitrification. The relative importance of sedimentary processes compared to processes in the water phase increases with hydraulic residence time and decreases with water depth. Lake Victoria has a long residence time 100 years and has a relatively low average depth $40 \mathrm{~m}$. Consequently, sedimentary processes become very important in Lake Victoria.

In lakes like Victoria with very long flushing times, sediment burial dominates the loss of nutrients except for those nutrients that are in gaseous phase. For example gaseous nitrogen can enter the lake from biological nitrogen fixation of atmospheric nitrogen, but it can also be lost from the lake by denitrification processes. Likewise, carbon (C), which is fixed into particulate can be lost by photosynthesis of carbon dioxide, can be returned to gaseous carbon dioxide by respiration and decomposition of particulate organic matter. On the contrary, nutrients like phosphorus $(\mathrm{P})$ and silicon (Si) can only be lost by sedimentation to permanent burial or at the outflow. Because of the long flushing time, losses at the outflow are minimal, and sediment burial dominates loss of $\mathrm{P}$ and $\mathrm{Si}$ from Lake Victoria waters.

Quantitative assessment of sedimentation is always difficult because sediment concentrations and settling rates are extremely variable, depending on the prevailing conditions at different locations e.g history of rain, wind, and waves which are location specifics. Recommended approach is to put out settling tubes (traps), vertically oriented cylinders from which trapped material is periodically collected and analysed.

To study the sedimentation status of the lake, Water Quality and Ecosystem Management Component of the LVEMP carried out sedimentation studies at different locations in the lake, to obtain comprehensive information on sedimentation and fluxes of particulate and dissolved nutrients between the water phase and the sediment both in lake waters and river mouth entering the lake. At Tanzanian side, the lake is fed by three major rivers namely Kagera in western part, Mara in eastern part and Simiyu in southeast part. All these rivers contribute sediments and nutrients.

\section{METHODOLOGY}

\section{(i) Sampling stations design}

The selected sampling stations were divided into two zones namely; Tanzania-littoral (TL) and Tanzania-Pelagic (TP). Systematically selected transects were established (Fig.5) and samples were collected at designated stations named TLs, and TPs for Tanzania littoral and pelagic waters respectively. During the fieldwork, sampling locations were geo-referenced for ease of identification for subsequent lake data collection. In Tanzanian part there are twenty-eight (28) stations of which eleven (11) are at shallow waters (littoral stations) and seventeen (17) at open waters (pelagic stations).

The exercise on data collection for sedimentation studies was done between November 2000 to March 2005 whereby one hundred ninety (190) samples were collected from littoral stations and three hundred and two (302) from pelagic waters respectively. Summary shown in Tables 1,2 and 3. 


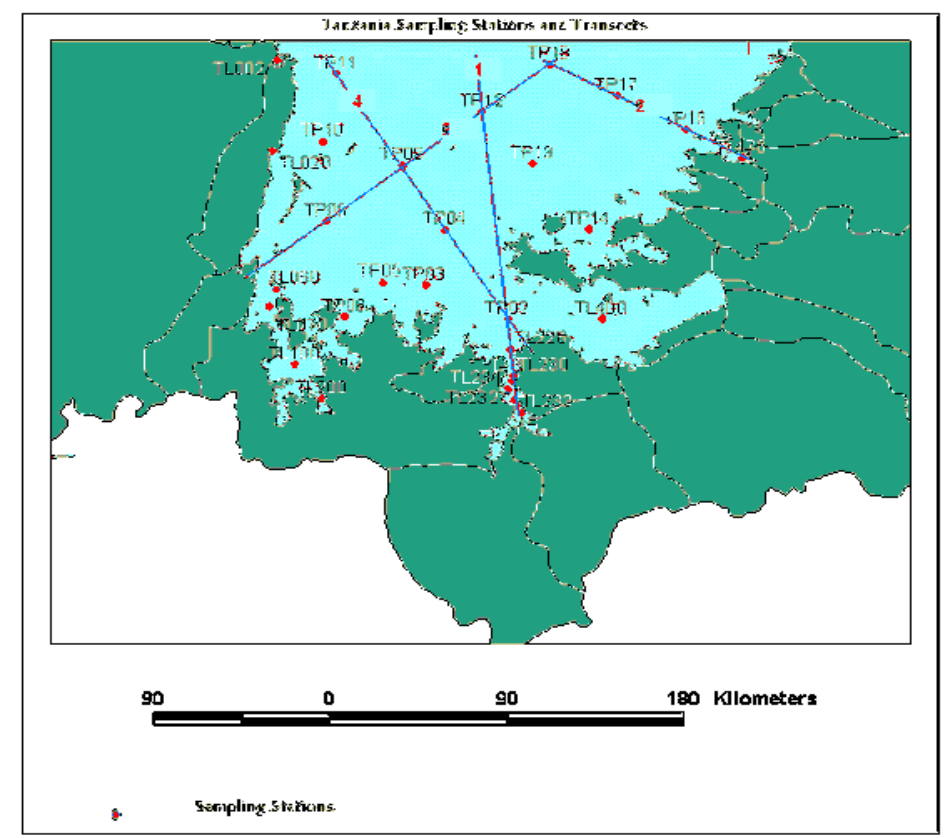

Fig.5 Monitoring stations in Lake Victoria (Tanzania part):

\section{(ii) Sampling procedure}

Three sets of sediment traps with diameters of 4.5 $\mathrm{cm}$ to $8.4 \mathrm{~cm}$ were vertically configured at three depths with open tops exposed to settling particles. The first set were fixed closer to the end of predetermined photic zone $(=2.3 \times$ Secchi depth) the second set at two meters $(2 \mathrm{~m})$ from the bottom while the third one fixed at the mid between the first and second sets. Traps were attached to fixed vertical line (rope), anchored at the bottom with weight and subsurface buoy at the upper part of water column to keep line vertically and attached at the top to buoys (Fig.6). After 1 - 2 days of exposure the traps were retrieved (Fig.7) and the volume of water in the traps was measured using a measuring cylinder and reserved in plastic sampling bottles ready for transportation to the laboratory for analysis. The trapped particles were sub sampled and collected on GF-C glass fibre filters (pore size $1 \mu \mathrm{m})$ to be analysed for parameters of interest, such as Total suspended solids-TSS, Loss of Ignition-LOI, Total Particulate Phosphorus-TPP, Total Biogenic Silica -PBSi and Total Particulate Carbon-TPC. 




Fig.6: Sketch of sediment traps configuration

Initially, duplicate traps were exposed at depths $0.2,0.4,0.6$ and $0.8 \mathrm{~m}$ above the bottom, so as to capture/trap resuspension from the bottom. After analysis, the results indicate that re-suspension is not interfering if traps are exposed from $2 \mathrm{~m}$ above the bottom.

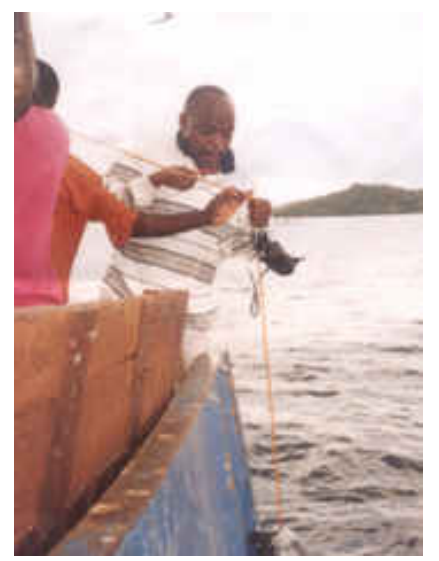

Fig. 7: Retrieving sediment traps

\section{ANALYSIS OF THE RESULTS AND DISCUSSION}

Sediments being inorganic or organic they come from catchments through erosion, or by chemical precipitation or they are produced by primary production and further metabolised through the food chains in the catchments and in the lake. Studies show that sediments play an important role in nutrient cycling in the aquatic environment and are responsible for transporting a significant proportion of many nutrients and contaminants (Bartram and Ballance, 1996).

Particles with a density higher than lake water sink to the lake bottom and can be captured by sediment traps. During sinking the particles are mineralised and the primary settling flux decreases with the trap exposure time. By reducing the exposure time to 1 - 2 days the mineralisation in the traps becomes negligible compared to the mineralisation during the sinking.

Sediments interact with lake water and soluble constituents in such a manner that they give many unique insights into limnological processes. As a consequence they provide important basic information on the geochemical origin, dispersion throughout the lake, and limnological fate of soluble and particulate constituents (Chapman, 1998).

Sediment concentrations and settling rates were found to be variable (Table 1 and 2); this indicates that Lake Victoria is not homogeneous. In data interpretation, the sedimentation rate, SR, defined as a mass of dry material deposited per unit area per unit time, is expressed in $\mathrm{mgm}^{-2} \mathrm{day}^{-1}$. Thus average settling rate during the exposure time $T$ becomes:

$\mathrm{SR}=(\mathrm{M} \times \mathrm{C}) / \mathrm{AT} \ldots \ldots \ldots \ldots \ldots \ldots \ldots \ldots \ldots \ldots . . . \ldots 2$

Where, $M$ = the dry mass of the whole sample 
$\mathrm{C}=$ the concentration of the chemical of interest, and

$\mathrm{A}=$ the trap collecting area. And $\mathrm{T}=$ the time of exposure

The tables 1 and 2 below shows that mean sedimentation rate at littoral stations for total particulate phosphorous (TPP) was about twice as compared to pelagic stations. The same situation was observed for total particulate carbon (TPC), however, total particulate silica did not show a clear pattern of variability between littoral and pelagic stations though there was a general tendency of decreasing towards the pelagic stations. Mean value for TPC /TPP sedimentation rate ratio was 117.61 for littoral and 90.74 for pelagic stations respectively compared to TBSi/TPP which was 3.15 for littoral and 2.10 for pelagic stations. The study suggests that organic material is high at the shoreline compared to offshore areas. These values are comparable with what was found by Machiwa and Muzuka (2002) at Magu Bay in Speke Gulf, the author found that the $\mathrm{C} / \mathrm{N}$ ratio values were decreasing with distance away from the shoreline. These results indicate contribution of organic material to the lake by plants and possibly due to anthropogenic and other natural inputs into the lake from the catchments.

Table 1 Flux Rates

\begin{tabular}{|c|c|c|c|}
\hline Location & TPP $\left[\mathrm{g} / \mathrm{m}^{2} / \mathrm{yr}\right]$ & $\mathrm{TBSi}\left[\mathrm{g} / \mathrm{m}^{2} / \mathrm{yr}\right]$ & $\mathrm{TPC}\left[\mathrm{g} / \mathrm{m}^{2} / \mathrm{yr}\right]$ \\
\hline Littoral Stations & 15.78 & 20.88 & 1152.97 \\
\hline Pelagic Stations & 9.50 & 18.35 & 573.30 \\
\hline
\end{tabular}

Table 2 TPC /TPP and TBSi/TPP sedimentation rate ratios

\begin{tabular}{|c|c|c|c|}
\hline Littoral Stations & TBSi/TPP ratio & Pelagic Stations & TBSi/TPP ratio \\
\hline Ratio & $0.16-22.86$ & Ratio & $0.20-8.75$ \\
\hline Mean ratio & 3.15 & Mean ratio & 2.10 \\
\hline
\end{tabular}

\begin{tabular}{|c|c|c|c|}
\hline Littoral Stations & TPC/TPP ratio & Pelagic Stations & TPC/TPP ratio \\
\hline Ratio & $71.88-207.73$ & Ratio & $1.00-190.74$ \\
\hline Mean ratio & 117.61 & Mean ratio & 90.74 \\
\hline
\end{tabular}

Table 3: Mean value of $\mathrm{C} / \mathrm{N}$ ratios, total accumulation rate ( $\mathrm{TO}-\mathrm{AR}$ in $\mathrm{g} / \mathrm{m}^{2} / \mathrm{yr}$ ), accumulation rates for organic carbon (OC-AR in $\mathrm{gC} / \mathrm{m}^{2} / \mathrm{yr}$ ) and nitrogen $\left(\mathrm{N}-\mathrm{AR}\right.$ in $\mathrm{gN} / \mathrm{m}^{2} / \mathrm{yr}$ ) for various short cores collected from the Magu Bay.

\begin{tabular}{|c|c|c|c|c|}
\hline CORE & C/N & Mass-AR $\left(\mathrm{g} / \mathrm{m}^{2} / \mathrm{yr}\right)$ & OC-AR $\left(\mathrm{gC} / \mathrm{m}^{2} / \mathrm{yr}\right)$ & $\mathrm{N}-\mathrm{AR}\left(\mathrm{gN} / \mathrm{m}^{2} / \mathrm{yr}\right)$ \\
\hline LV 4 & 13.41 & 33.40 & 8.82 & 0.77 \\
\hline LV 5 & 14.67 & 59.98 & 28.36 & 2.27 \\
\hline LV 11 & 11.98 & 22.17 & 12.00 & 1.15 \\
\hline LV 15 & 15.89 & 23.35 & 11.65 & 0.83 \\
\hline LV 22 & 14.40 & 240.66 & 57.25 & 4.37 \\
\hline LV 24 & 15.98 & 20.50 & 6.92 & 0.51 \\
\hline LV 30 & 15.86 & 92.59 & 27.39 & 2.02 \\
\hline LV 31 & 16.10 & 134.49 & 25.53 & 1.90 \\
\hline LV 36 & 18.94 & 62.88 & 21.93 & 1.36 \\
\hline
\end{tabular}

Data source: Machiwa and Muzuka (2002 ) Sedimentation Studies at the Simiyu River Mouth - Magu Bay, Speke Gulf, Lake Victoria, Tanzania). 


\section{Composition of Sediments (nutrients)}

To determine the settling rates, regressions curves were performed and the results show that silica has high sedimentation rate compared to phosphorous.
In contrary, phosphorous and carbon were of the same magnitude especially in littoral stations, while phosphorous dominated in open waters Fig.8 (a. c).
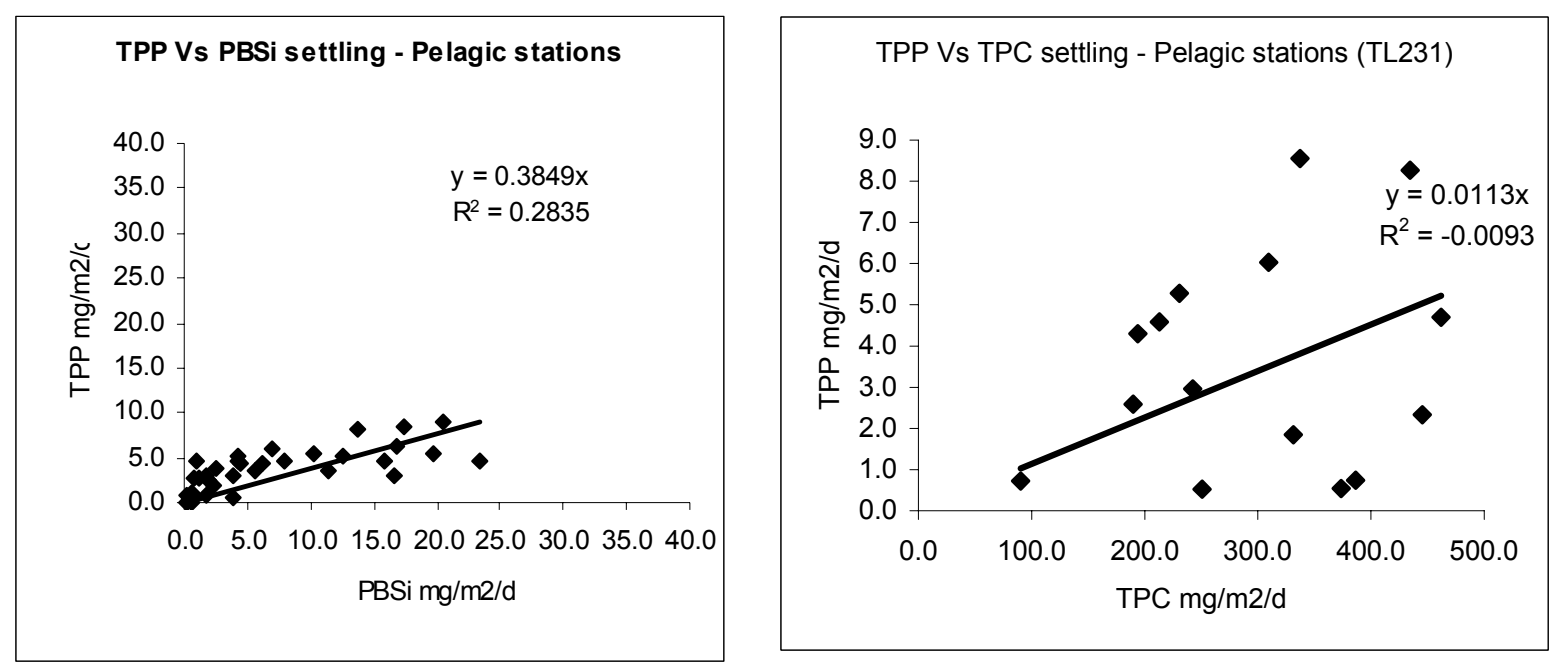

(a)

(b)

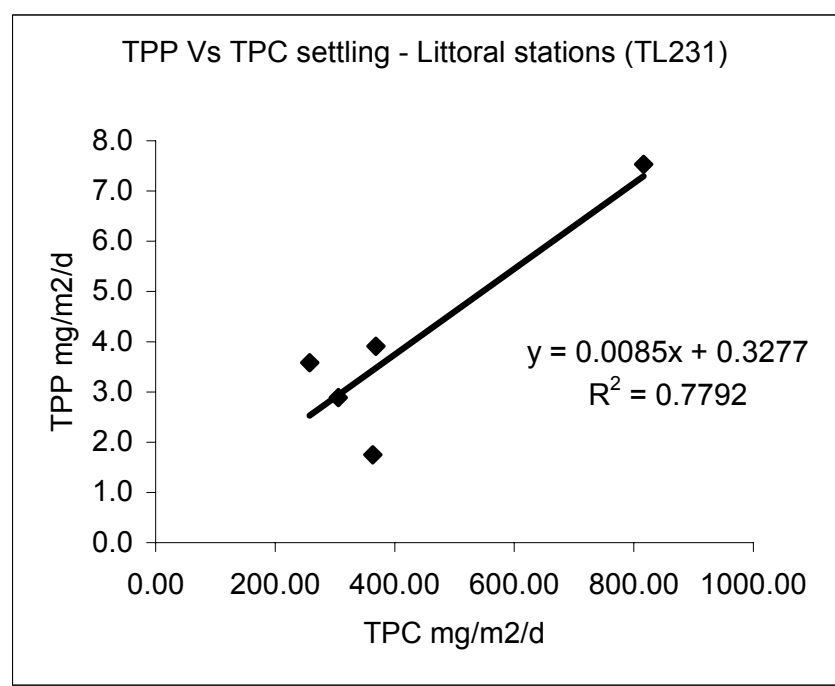

Fig. 8 Nutrients composition of the sediments

(c)

\section{Sedimentation velocity}

To obtain sedimentation velocity $(\mathrm{m} / \mathrm{d})$, regressions between sedimentation rates $(\mathrm{mg} / \mathrm{m} 2 / \mathrm{d})$ and the parameters concentration $(\mathrm{mg} / \mathrm{m} 3)$ at the exposure depth were performed. The obtained sedimentation velocity values for TPP at littoral and pelagic stations were 0.117 and $0.031(\mathrm{~m} / \mathrm{d})$ respectively, while those for TPC were 0.103 and 0.086 . The results show that sedimentation velocity in littoral stations (bays and gulfs) is much higher than in the pelagic area. This could possibly be due to combination of both the input from the catchment and the processes within the lake. Further more, the study indicate that sedimentation velocity of PBSi was 0.14 , which is higher compared to velocities for TPP and TPC. (Fig. 9) 

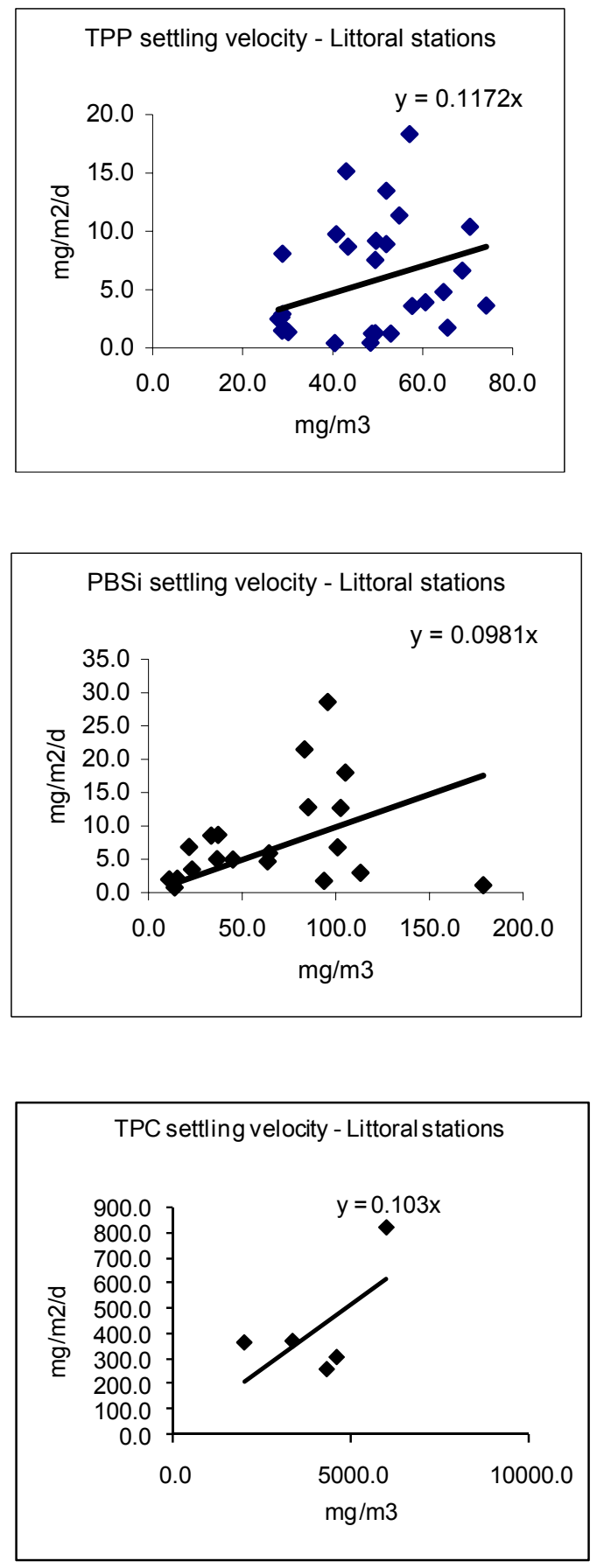
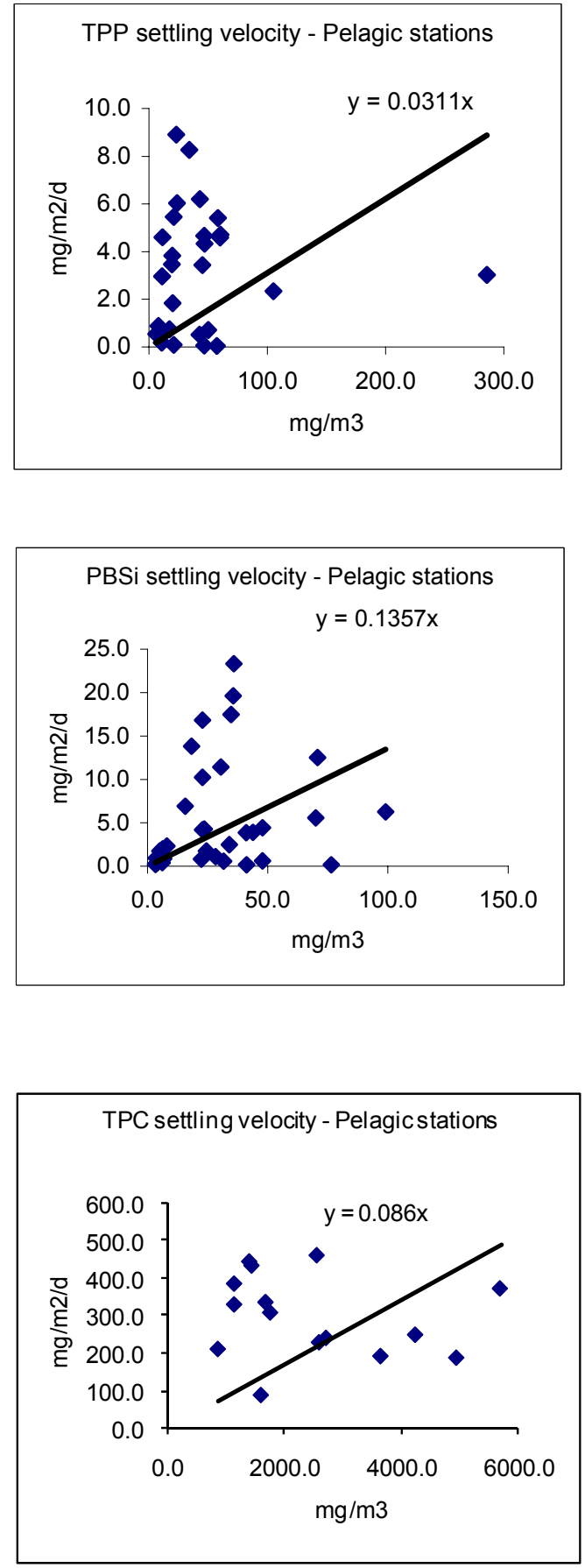

Fig. 9: Sediment Settling Velocities

The obtained data show that nutrients (TP and TN) concentration increases with depth, particularly in open waters. However, the study demonstrate that more nutrient levels in sediments are highest at gulfs, river mouths, bays and at some sections of the littoral zone whereby periodical proliferation of water hyacinth, increased oxygen demand and reduced biodiversity can visually be witnessed (Fig. $10 a-b)$ 

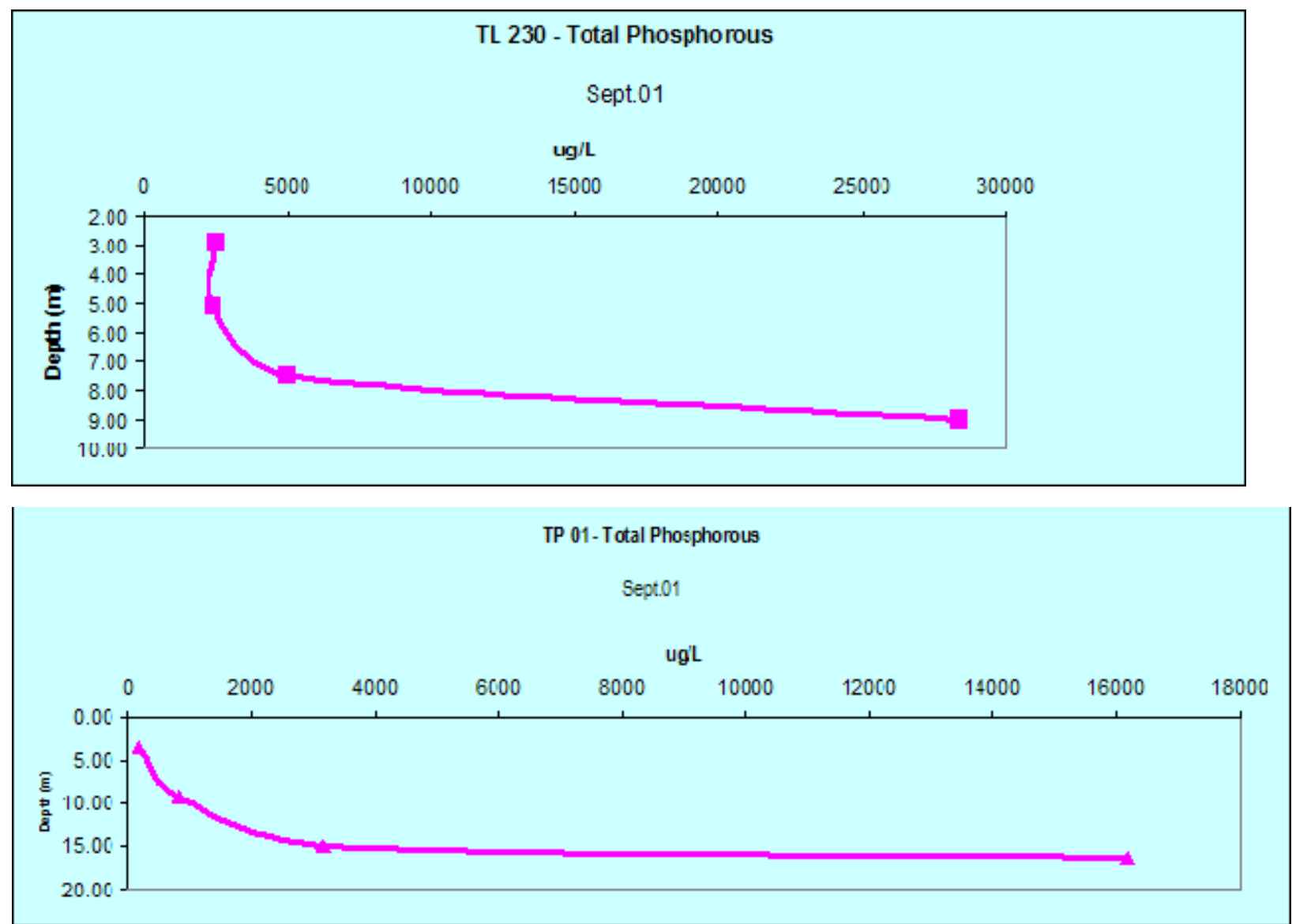

Fig. 10 Nutrients distribution at TL230 (Littoral) and PT01 (Pelagic) stations

\section{A spatial variation of nutrients along transects}

The study shows that contribution of the sedimentation process to the eutrophication of the lake is more significant in near shore areas than in open waters such as at the gulfs, bays and river mouths due to high sedimentation inputs from the catchments. Poor land use in the catchment, lack of

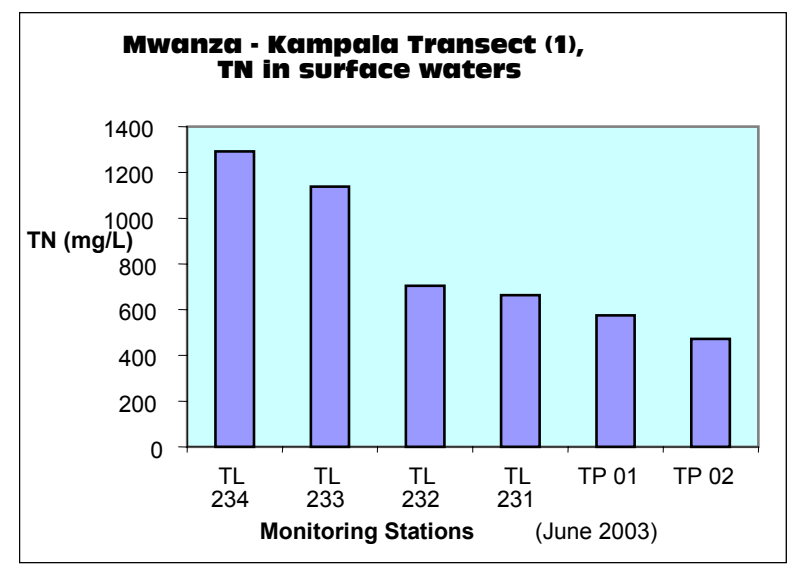

Fig. 9a municipal and industrial effluents treatment facilities and poor handling of daily generated solid wastes have triggered transportation of nutrients in the lake via either rivers, surface run off and direct flow of partially or non treated wastes. Furthermore, the study observed that nutrients concentrations were decreasing with distance from inshore to offshore waters (Fig.11a - e).

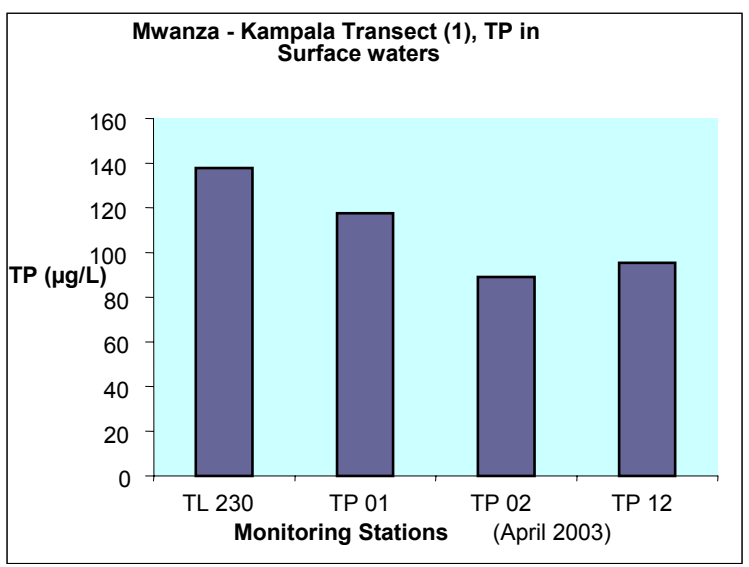

Fig. $9 b$ 


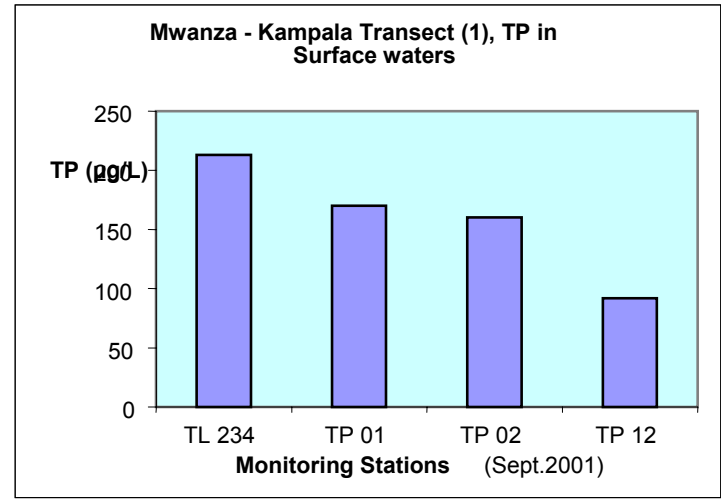

Fig. 9c

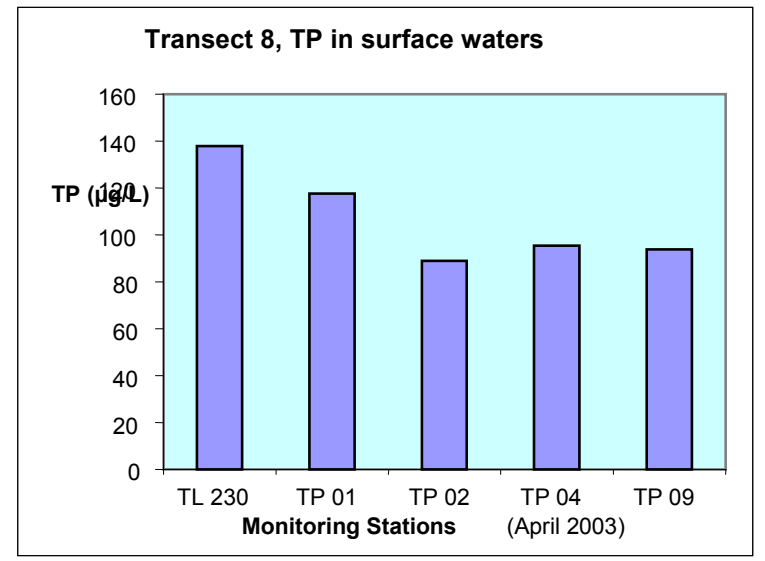

Fig. 9d

Fig. (10a -e): spatial variation of nutrients in sediments

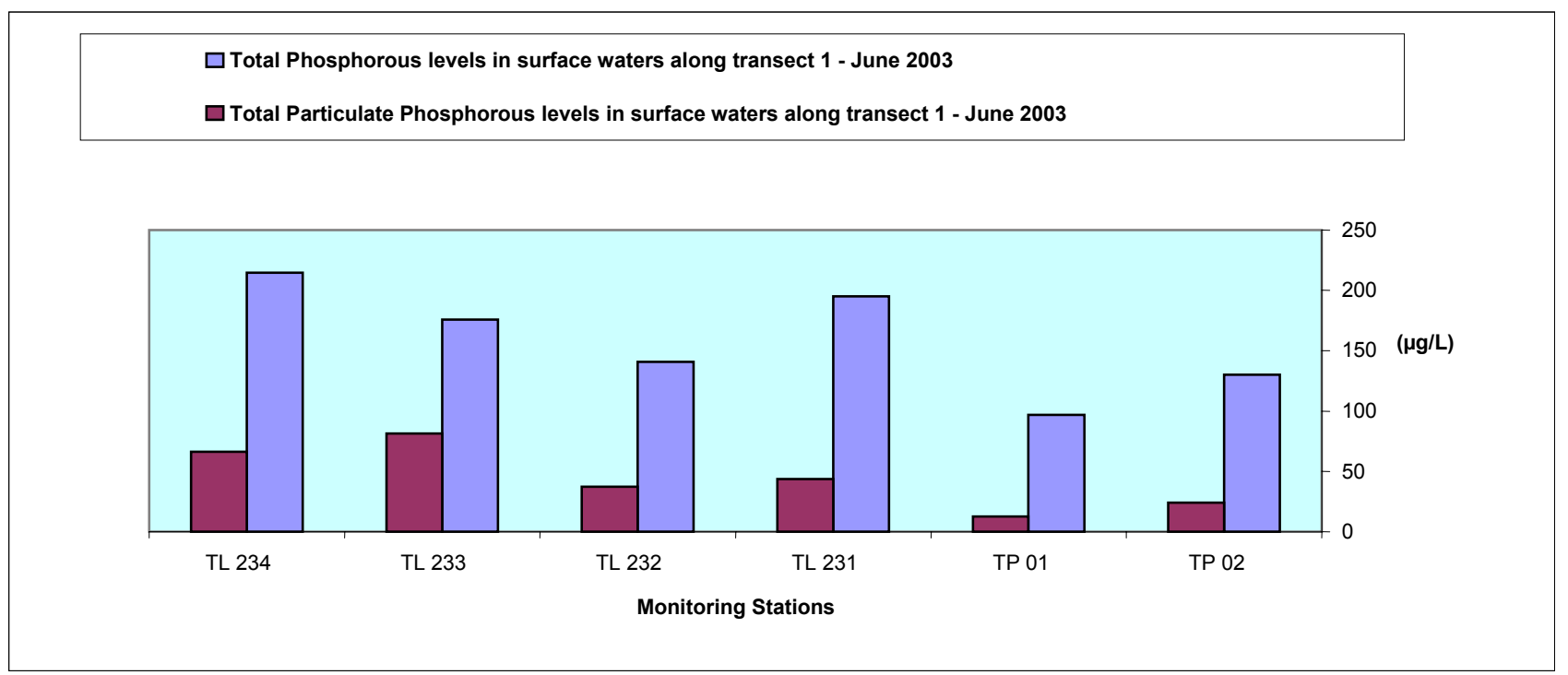

Fig. (11a -e): spatial variation of nutrients in sediments

\section{Rivers sediments to Lake Victoria}

River mouths, Gulfs and Bays are the potential areas that receive the highest loads of sediments which are rich in nutrients and other pollutants from the catchment including surface runoffs and agricultural areas thereby causing the lake to continue filling up and affecting the quality of water.
Many river mouths, gulfs and bays are the important areas for fish breeding and fishing grounds.

According to data collected from Kagera River (measured at Nyakanyasi), results indicate that the suspended sediment loads (annual mean) increased from 400kT/year in 1971 to $600 \mathrm{kT} /$ year in 1972 (Chadha, 1972). Currently, it is estimated that the suspended sediment load at the same point is $1400 \mathrm{kT} /$ year (Fig 12), which is about 3.5 times that of 1971 (Machiwa and Muzuka, 2002). 


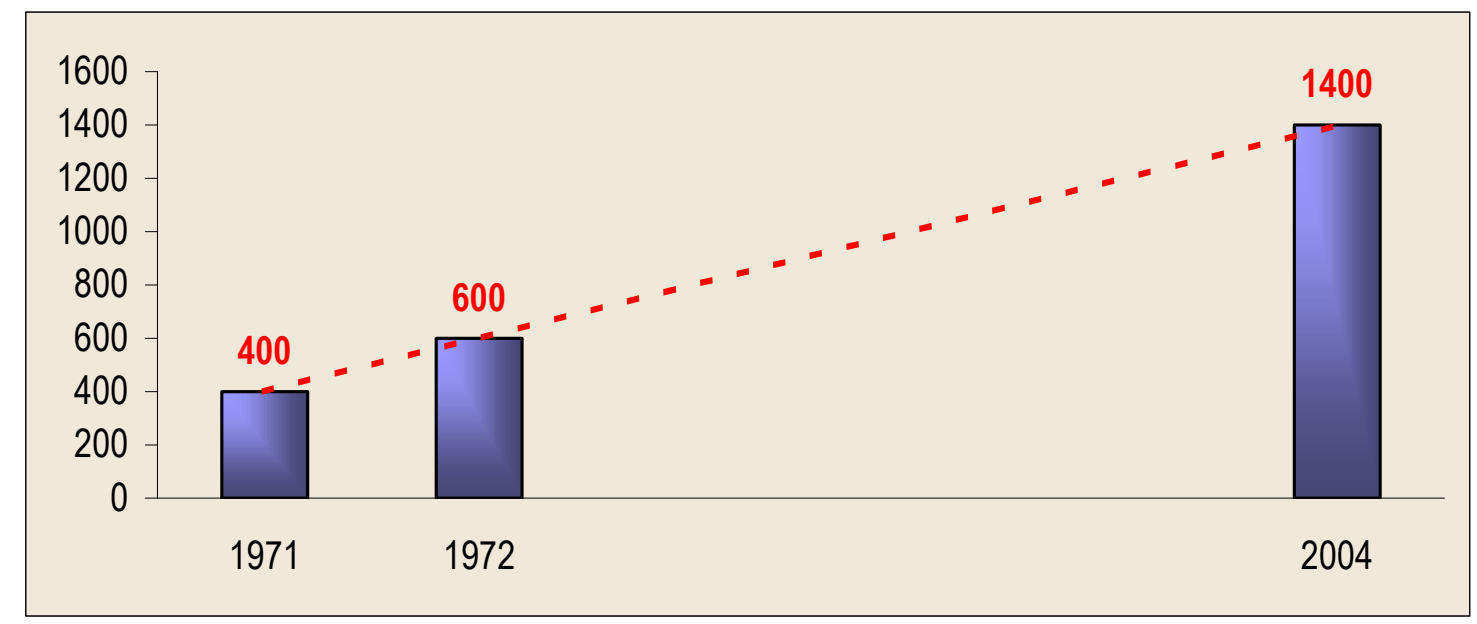

Fig.12: Suspended sediment load trend at Nyakanyasi -Kagera River

\section{Physical indicators of lake pollution}

The natural physical characteristics of the lake has significantly undergone through changes that threats not only aquatics but also the people who mainly depends on the lake for their economy and livelihood as well. The results obtained from this study show that concentration of suspended solids are higher at the littoral stations compared to pelagic stations.

This could have been attributed by human impacts in the lake adjacent areas leading to nutrient inflow in form of sediments.
It is also observed that littoral stations near highly residential areas and urban centres have higher turbidity, suspended solids and discolouration of lake water that accompanied by low water clarity (transparency) than those in areas with low or no settlements (Fig.13a - b). As a result, light penetration is very much limited to few centimetres in shallow areas that are associated with high concentration of suspended particles as the result of luxuriant growth of micro-algae (Machiwa and Muzuka, 2002). 

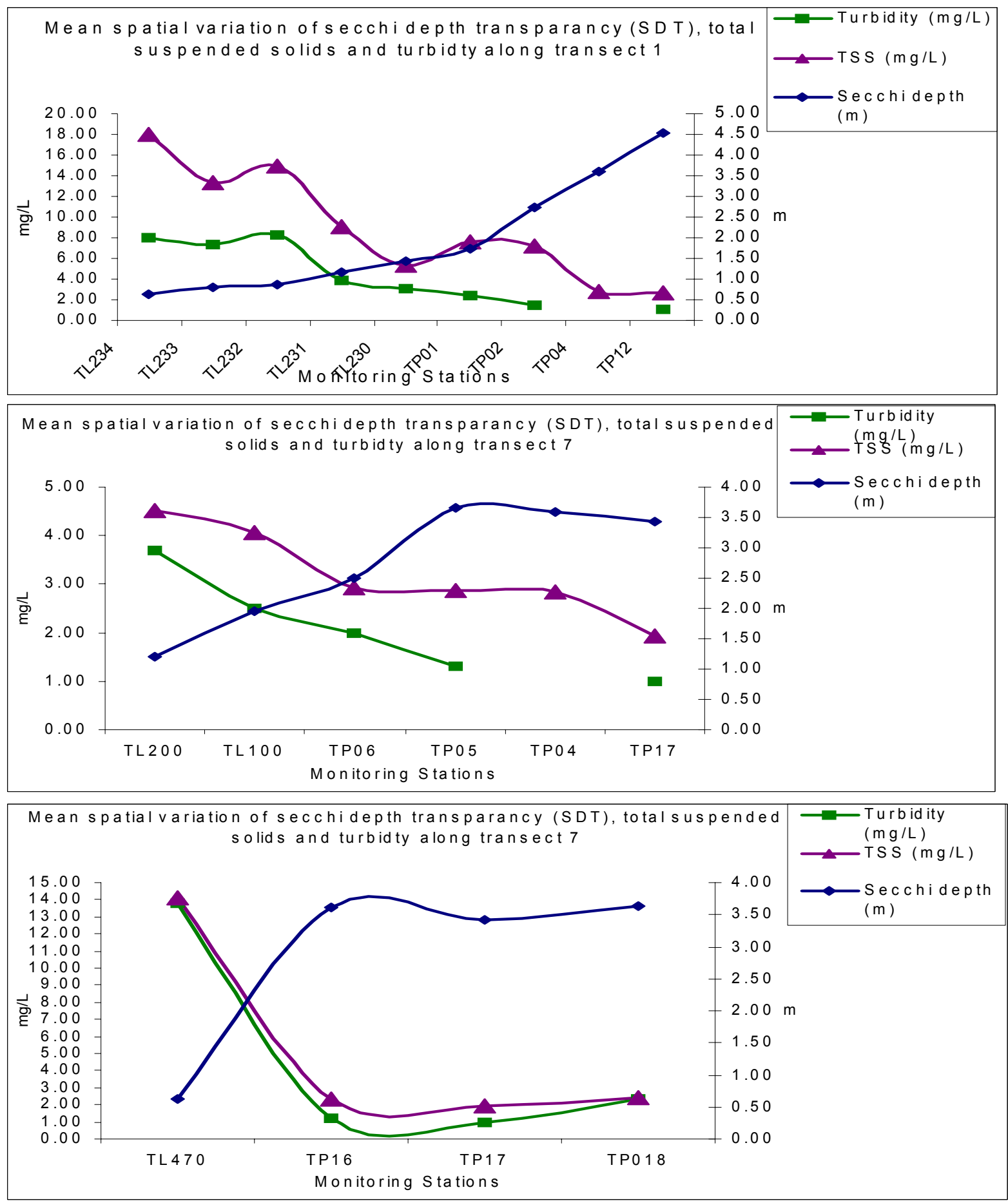

Fig.13: Mean spatial variation of SDT, SS and turbidity.

\section{CONCLUSION}

- The results show that sedimentation rates are highest at the littoral stations compared to pelagic stations.

- The stoichiometric composition of the settling material indicates nitrogen limitation and a non-dominance of diatoms. The differences in sinking velocities indicate that the settling material consists of dead and living material with a contribution of diatoms. 
- It should be noted that sedimentation patterns observed over a relatively short time period (5 years) may not accurately represent patterns over longer time periods. Therefore, the Water Quality Monitoring should plans to continue the annual monitoring of the Lake sediment for over longer time periods, so that information on variability in the rates of sedimentation can be meaningful and reliable.

\section{RECOMMENDATON}

- Tremendous variability of such measurements means vast amounts of data must be collected before average values or trends in them can be meaningfully estimated

- This study calls for short and long terms remedial action plans to rescue the lake from becoming old before its time.

- The results may be used to determine the water quality in the Lake and to set water quality objectives to protect water uses. Also, these results may be used to recommend and evaluate possible remediation activities.

- $\quad$ Reducing the man made sources of nutrients will help reduce the frequency and intensity of algae blooms although will not eliminate them completely.

\section{REFERENCES}

Bartram, J., and Balance, R., (Ed), (1996). Water Quality Monitoring. Apractical guide to the design and implementation of freshwater quality studies and monitoring programmes. $I^{\text {st }}$ edition Chapman \& Hall, London

Chadha, S.P., (1972) Sediment and water Quality Characteristics (Unpublished): HydroMeteorological Survey of the catchments of Lakes Victoria, Kyoga, and Albert.

Chapman, D. (Ed), (1998). Water Quality Assessments. A guide to the use of Biota, Sediments and

Water in Environmental monitoring. $2^{\text {nd }}$ edition.

Machiwa, F., and Muzuka, A., (2002.) Sedimentation in Magu bay. In Machiwa., F (ed.), 2002 Nutrients, micro-algae, sedimentation and sediment associations at the mouth of Simiyu river (Magu bay of Speke gulf) Lake Victoria, LVEMP,Tanzania, 